\title{
Health Care Utilization Among U.S. Adults With Inflammatory Bowel Disease, 2015-2016
}

by Emily P. Terlizzi, M.P.H., James M. Dahlhamer, Ph.D., National Center for Health Statistics; Fang Xu, Ph.D., Anne G. Wheaton, Ph.D., and Kurt J. Greenlund, Ph.D., National Center for Chronic Disease Prevention and Health Promotion

\section{Abstract}

Objective-To measure health care utilization among adults with inflammatory bowel disease (IBD) and compare with adults without IBD.

Methods-Adults aged 18 and over with IBD (1.2\%) and without IBD were identified from the 2015 and 2016 National Health Interview Survey $(n=66,610)$. This study presents age-adjusted percentages and model-adjusted prevalence ratios (APRs) of selected health service use to identify differences by IBD status. IBD status and use of health care services are based on self-reports.

Results - Compared with adults without IBD, adults with IBD were more likely to have visited any doctor or mental health provider in the past 12 months. IBD was also associated with higher prevalence of being prescribed medication, and having received acute care services, such as emergency room visits, overnight hospitalizations, or surgeries. Differences by IBD status were greatest for visiting a specialist (APR: 1.98; 95\% confidence interval [CI]: $1.82-2.14$ ) and home visits (APR: $1.80 ; 95 \%$

CI: $1.25-2.59)$ in the past 12 months.

Conclusions - Adults with IBD had higher health service use than adults without IBD. Future studies may assess patient characteristics and outcomes associated with increased utilization among IBD patients.

Keywords: IBD • ulcerative colitis $\bullet$ Crohn's disease $・$ National Health Interview Survey

\section{Introduction}

Inflammatory bowel disease (IBD), which includes Crohn's disease and ulcerative colitis, causes chronic inflammation in the gastrointestinal tract. In 2015 and 2016, an estimated 3.1 million (1.2\%) U.S. adults reported having received a diagnosis of IBD (1). While IBD is generally nonfatal, people with IBD are often heavy users of the health care system. IBD patients often take medications and visit doctors frequently to achieve and maintain remission, and severe cases or those not responding to medications may require hospitalizations and surgeries $(2,3)$. Adults with IBD are also more likely to have comorbidities, such as cardiovascular disease, cancer, arthritis, and liver conditions (1). As IBD patients are usually immunocompromised (4), complications and disease management all contribute to greater health care utilization. This high utilization may lead to increased medical cost and increased financial burden of care for people with IBD.

While previous work has examined health behaviors (1) and preventive services use among adults with IBD (5), recent nationally representative data on overall health care use for this population are lacking. This report uses data from the National Health Interview Survey (NHIS) to provide nationally representative estimates of utilization of selected health care services among adults with IBD and examines differences in utilization compared with adults without IBD.

\section{Methods}

Data were drawn from 66,610 sample adults aged 18 and over who participated in either the 2015 or 2016 NHIS. A multipurpose, nationally representative health survey of the civilian, noninstitutionalized U.S. population, NHIS is conducted annually by the National Center for Health Statistics. Interviewers with

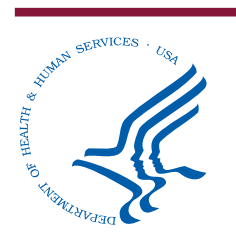

\section{U.S. DEPARTMENT OF HEALTH AND HUMAN SERVICES Centers for Disease Control and Prevention National Center for Health Statistics}


the U.S. Census Bureau administer the questionnaire using computer-assisted personal interviewing. Telephone interviewing is permitted to complete missing portions of the interview. NHIS consists of both a core set of questions that remain relatively unchanged from year to year, as well as supplemental questions that are not asked every year. The question regarding diagnosis of Crohn's disease or ulcerative colitis was included as a 2-year supplement in the Sample Adult interview in the 2015-2016 NHIS. The final response rate for the Sample Adult module was $55.2 \%$ in 2015 and $54.3 \%$ in $2016(6,7)$.

Age-adjusted percentages and $95 \%$ confidence intervals (CI) are presented for selected health service utilization measures by IBD status, using the projected 2000 U.S. population as the standard population (8). Also presented are adjusted prevalence ratios (with 95\% CI) derived from multivariable logistic regression models, controlling for possible confounders (5): age, race and Hispanic origin, sex, marital status, education, employment status, health insurance coverage, poverty level (calculated using NHIS imputed income files), and region. As the purpose of this analysis was to measure the total health care utilization among adults with IBD more generally, models did not control for comorbidities. Details on the outcome measures included in this report can be found in Table 1.

All analyses were weighted using final sample adult weights adjusted for nonresponse and calibrated to population control totals and conducted in SAScallable SUDAAN 11.0.3 software (RTI International, Research Triangle Park, North Carolina) to account for the stratified, complex cluster sampling design of NHIS. All differences discussed are significant $(p<0.05)$ unless otherwise noted.

\section{Results}

In 2015 and 2016, utilization was higher for all measures among the $1.2 \%$ of adults with IBD compared with adults without IBD (Table 2). Details on the distributions of sociodemographic characteristics of adults with and without IBD using these data have been published elsewhere (5). The percentage who had seen or talked to a health professional in the past 12 months was higher among adults with IBD than among adults without IBD. In particular, adults with IBD were nearly twice as likely to have seen a specialist in the past 12 months, and $74 \%$ more likely to have seen a mental health provider in the past 12 months compared with adults without IBD. Adults with IBD were $32 \%$ more likely to have been prescribed any medication in the past 12 months and $80 \%$ more likely to have had any home visits in the past 12 months compared with adults without IBD. The percentage of adults with IBD who had visited a health professional in an office, clinic, or some other place four or more times in the past 12 months was higher than among those without IBD. Finally, adults with IBD were also more likely to report any emergency room visits, overnight hospital stays, and surgeries in the past 12 months.

\section{Discussion}

This study presents overall health care use among adults with IBD compared with adults without IBD using a recent, nationally representative data source. Adults with IBD had higher health service use than adults without IBD for all measures examined in this study.

This finding is consistent with several other studies $(3,9,10)$, despite differences in year, data source (e.g., survey data, insurance claims data), or scope of coverage (e.g., national, regional, commercially insured). For example, prior studies have found that those with IBD were more likely to have used prescription medication in the past 3 months, as well as to have visited a physician, a specialist, an emergency room, and have had hospitalizations and surgeries in the past 12 months, compared with adults without IBD $(3,9,10)$. In one study, adults who were diagnosed with IBD 16 years earlier were still more likely to have used prescription medication in the past 3 months, visited an emergency room, or seen a specialist in the past 12 months, compared with adults without IBD (3). Another study found that from 2005 through 2016, emergency department visits and hospital admissions for IBDrelated care have been increasing. This change was more likely to be seen among patients who were inadequately insured, socioeconomically disadvantaged, or had limited access to health care (11). While IBD-specific surgery rates have been decreasing recently, likely due to newer, effective treatments and medications developed for IBD (12), adults with IBD had a higher likelihood of having any surgery compared with those without IBD. This study found that specialist visits were more common among adults with IBD than among adults without IBD. Although NHIS does not collect details about specific medical specialties, other studies have also shown that visits to gastroenterologists were more frequent among those with IBD (9). Furthermore, adults with IBD were more likely to have seen a mental health professional in the past 12 months compared with adults without IBD. Many studies have shown that mental health conditions are prevalent among IBD patients (13-15), with one systematic review finding prevalence rates of $20 \%$ for anxiety, and $15 \%$ for depression (13). However, other studies have found that one-third of IBD patients who met diagnostic criteria for depression and two-thirds of those who met diagnostic criteria for anxiety were undiagnosed, which indicates that the true prevalence of mental health conditions may be even higher in this population (16).

This report does not differentiate the reasons for health service use; it measures the overall utilization among adults with and without IBD. These findings of higher utilization among those with IBD may reflect both care for IBD as well as for comorbidities, which are known to be more prevalent among those with IBD. This high overall utilization may lead to increased medical cost. Based on an estimated 1.6 million people diagnosed with IBD, the annual direct and indirect costs of IBD in the United States was estimated to be between $\$ 14.6$ billion and $\$ 31.6$ billion (17). However, a more recent national study using NHIS data estimated that 3.1 million adults have IBD (1); therefore, the current total costs of IBD in the United States may be much higher. Furthermore, total direct costs 
of IBD have been increasing in recent years, likely a result of increased use of biologic medications (18). Biologic medications involve infusions and are considerably more expensive than other forms of IBD medication (19). Other factors, such as use of corticosteroids or frequent hospitalizations, have also been determined to be predictors of particularly high utilization and costs among IBD patients (20).

The primary advantage of this study is the use of a large, nationally representative data source to provide more recent estimates of several measures of health care utilization among adults with IBD. However, this report is subject to at least four limitations. First, because NHIS responses are selfreported and not corroborated by medical records, they are subject to reporting bias. Second, the question about IBD status did not differentiate Crohn's disease from ulcerative colitis. Therefore, assessing health care utilization by specific condition is not possible. Third, as respondents were not asked the reasons for receiving health care services, it is not clear how much health care received by adults with IBD was due to their IBD or due to other, non-IBD reasons (e.g., comorbidities, accidents, or injuries). Lastly, institutionalized adults are not included in the NHIS sample. These adults may have high health care use, so estimates of health care use presented in this report may be an underestimate.

In conclusion, these estimates of higher health care services use among adults with IBD, compared with those without IBD, provide a reference of the burden experienced by these patients and the impact on the U.S. health care system, and can inform physicians and health care policy makers aiming to improve IBD care by increasing important preventive care utilization and minimizing potentially avoidable health services. Future studies may assess associations between patient characteristics and health care utilization and the subsequent outcomes among IBD patients.

\section{References}

1. Xu F, Dahlhamer JM, Zammitti EP, Wheaton AG, Croft JB. Health-risk behaviors and chronic conditions among adults with inflammatory bowel disease-United States, 2015 and 2016. MMWR Morb Mortal Wkly Rep 67(6):190-95. 2018.

2. Carter MJ, Lobo AJ, Travis SP. Guidelines for the management of inflammatory bowel disease in adults. Gut 53(suppl 5):v1-16. 2004.

3. Longobardi T, Jacobs P, Bernstein $\mathrm{CN}$. Utilization of health care resources by individuals with inflammatory bowel disease in the United States: A profile of time since diagnosis. Am J Gastroenterol 99(4):650-5. 2004.

4. Rahier JF, Magro F, Abreu C, Armuzzi A, Ben-Horin S, Chowers $\mathrm{Y}$, et al. Second European evidencebased consensus on the prevention, diagnosis and management of opportunistic infections in inflammatory bowel disease. J Crohn Colitis 8(6):443-68. 2014.

5. Xu F, Dahlhamer JM, Terlizzi EP, Wheaton AG, Croft JB. Receipt of preventive care services among US adults with inflammatory bowel disease, 2015-2016. Dig Dis Sci 64(7):1798-1808. 2019.

6. National Center for Health Statistics. National Health Interview Survey: Survey description, 2015. Hyattsville, MD. 2016.

7. National Center for Health Statistics. National Health Interview Survey: Survey description, 2016. Hyattsville, MD. 2017.

8. Klein RJ, Schoenborn CA. Age adjustment using the 2000 projected U.S. population. Healthy People 2010 Stat Notes. Jan(20):1-10. 2001.

9. Kappelman MD, Porter CQ, Galanko JA, Rifas-Shiman SL, Ollendorf DA, Sandler RS, Finkelstein JA. Utilization of healthcare resources by U.S. children and adults with inflammatory bowel disease. Inflamm Bowel Dis 17(1):62-8. 2011.

10. Longobardi T, Bernstein CN. Health care resource utilization in inflammatory bowel disease. Clin Gastroenterol Hepatol 4(6):731-43. 2006.
11. Ma C, Smith MK, Guizzetti L, Panaccione R, Kaplan GG, Novak $\mathrm{KL}$, et al. Assessing national trends and disparities in ambulatory, emergency department, and inpatient visits for inflammatory bowel disease in the United States (2005-2016).

Clin Gastroenterol Hepatol

18(11):2500-9. 2020.

12. Frolkis AD, Dykeman J, Negron ME, Debruyn J, Jette N, Fiest KM, et al. Risk of surgery for inflammatory bowel diseases has decreased over time: A systematic review and metaanalysis of population-based studies. Gastroenterology 145(5):996-1006. 2013.

13. Neuendorf R, Harding A, Stello N, Hanes D, Wahbeh H. Depression and anxiety in patients with inflammatory bowel disease: A systematic review. J Psychosom Res 87(8):70-80. 2016.

14. Walker JR, Ediger JP, Graff LA, Greenfeld JM, Clara I, Lix L, et al. The Manitoba IBD cohort study: A population-based study of the prevalence of lifetime and 12-month anxiety and mood disorders. Am J Gastroenterol 103(8):1989-97. 2008.

15. Bhandari S, Larson ME, Kumar N, Stein D. Association of inflammatory bowel disease (IBD) with depressive symptoms in the United States population and independent predictors of depressive symptoms in an IBD population: A NHANES study. Gut Liver 11(4):512-9. 2017.

16. Lewis K, Marrie RA, Bernstein CN, Graff LA, Patten SB, Sareen J, et al. The prevalence and risk factors of undiagnosed depression and anxiety disorders among patients with inflammatory bowel disease. Inflamm Bowel Dis 25(10):1674-80. 2019.

17. The facts about inflammatory bowel diseases. Crohn's \& Colitis Foundation of America website. New York, 2014. Available from: https://www.crohnscolitisfoundation. org/sites/default/files/2019-02/ Updated\%20IBD\%20Factbook.pdf. 
18. Targownik LE, Kaplan GG, Witt J, Bernstein CN, Singh H, Tennakoon A, et al. Longitudinal trends in the direct costs and health care utilization ascribable to inflammatory bowel disease in the biologic era: Results from a Canadian population-based analysis. Am J Gastroenterol 115(1):128-37. 2020.

19. Yu H, MacIsaac D, Wong JJ, Sellers ZM, Wren AA, Bensen R, et al. Market share and costs of biologic therapies for inflammatory bowel disease in the United States. Aliment Pharmacol Ther 47(3):364-70. 2018.

20. Limsrivilai J, Stidham RW, Govani SM, Waljee AK, Huang W, Higgins PDR. Factors that predict high health care utilization and costs for patients with inflammatory bowel diseases. Clin Gastroenterol Hepatol 15(3):385-92. 2017. 
Table 1. List of survey questions and variable definition of selected health care utilization measures

\begin{tabular}{|c|c|c|}
\hline Health care utilization measure & 2015-2016 NHIS question ${ }^{1}$ & Type of respondent \\
\hline $\begin{array}{l}\text { Seen or talked to any health care professional } \\
\text { in past } 12 \text { months }\end{array}$ & $\begin{array}{l}\text { About how long has it been since you last saw or } \\
\text { talked to a doctor or other health care professional } \\
\text { about your own health? Include doctors seen while a } \\
\text { patient in a hospital. }\end{array}$ & Sample adult \\
\hline Seen or talked to a specialist in past 12 months & $\begin{array}{l}\text { [During the past } 12 \text { months, have you seen or talked to } \\
\text { any of the following health care providers about your } \\
\text { own health?..... A medical doctor who specializes } \\
\text { in a particular medical disease or problem (other } \\
\text { than obstetrician/gynecologist, psychiatrist, or } \\
\text { ophthalmologist)? }\end{array}$ & Sample adult \\
\hline $\begin{array}{l}\text { Seen or talked to a mental health professional } \\
\text { in past } 12 \text { months }\end{array}$ & $\begin{array}{l}\text { [During the past } 12 \text { months, have you seen or talked to } \\
\text { any of the following health care providers about your } \\
\text { own health?.....] A mental health professional such as a } \\
\text { psychiatrist, psychologist, psychiatric nurse, or clinical } \\
\text { social worker. }\end{array}$ & Sample adult \\
\hline Prescribed any medication in past 12 months & $\begin{array}{l}\text { During the past } 12 \text { months, were you prescribed } \\
\text { medication by a doctor or other health professional? }\end{array}$ & Sample adult \\
\hline $\begin{array}{l}\text { Had four or more office visits with a health professional } \\
\text { in past } 12 \text { months }\end{array}$ & $\begin{array}{l}\text { During the past } 12 \text { months, how many times have you } \\
\text { seen a doctor or other health care professional about } \\
\text { your own health at a doctor's office, a clinic, or } \\
\text { some other place? Do not include times you were } \\
\text { hospitalized overnight, visits to hospital emergency } \\
\text { rooms, home visits, dental visits, or telephone calls. }\end{array}$ & Sample adult \\
\hline Any home visits in past 12 months & $\begin{array}{l}\text { During the past } 12 \text { months, did you receive care at } \\
\text { home from a nurse or other health care professional? }\end{array}$ & Sample adult \\
\hline $\begin{array}{l}\text { Any visits to a hospital emergency room } \\
\text { in past } 12 \text { months }\end{array}$ & $\begin{array}{l}\text { During the past } 12 \text { months, how many times have you } \\
\text { gone to a hospital emergency room about your own } \\
\text { health (This includes emergency room visits that } \\
\text { resulted in a hospital admission.)? }\end{array}$ & Sample adult \\
\hline Any overnight hospital stays in past 12 months & $\begin{array}{l}\text { [Have you/Including all infants born in a hospital, has } \\
\text { anyone in the family] been hospitalized overnight in the } \\
\text { past } 12 \text { months? Do not include an overnight stay in } \\
\text { the emergency room. } \\
\text { If yes: Who was in a hospital overnight? }\end{array}$ & Family respondent ${ }^{2}$ \\
\hline Any surgeries in past 12 months & $\begin{array}{l}\text { During the past } 12 \text { months, have you had surgery or } \\
\text { other surgical procedures either as an inpatient or } \\
\text { outpatient? }\end{array}$ & Sample adult \\
\hline
\end{tabular}

${ }^{1}$ More information about the survey questionnaire is available at the following websites: 2015 National Health Interview Survey: ftp://ftp.cdc.gov/pub/Health_Statistics/NCHS/Survey_Questionnaires/

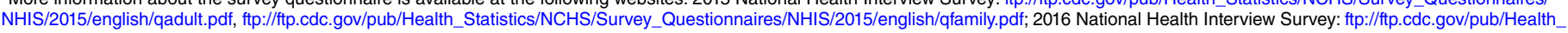
Statistics/NCHS/Survey_Questionnaires/NHIS/2016/english/qadult.pdf, ftp://ftp.cdc.gov/pub/Health_Statistics/NCHS/Survey_Questionnaires/NHIS/2016/english/qfamily.pdf. ${ }^{2}$ Measure is based on report about the sample adult from the family respondent. In some cases, the family respondent is selected as the sample adult, but if not, this measure is based on a proxy report.

NOTE: Data are based on household interviews of a sample of the civilian noninstitutionalized population.

SOURCE: National Center for Health Statistics, National Health Interview Survey, 2015-2016, Family Core and Sample Adult Core components. 
Table 2. Health care utilization, by inflammatory bowel disease status among adults aged 18 and over: United States, 2015-2016

\begin{tabular}{|c|c|c|c|c|c|c|c|}
\hline \multirow[b]{2}{*}{ Health care utilization measure ${ }^{1}$} & \multicolumn{2}{|c|}{ Total } & \multicolumn{2}{|c|}{ Adults with IBD } & \multicolumn{2}{|c|}{ Adults without IBD } & \multirow{2}{*}{$\begin{array}{c}\text { Model-adjusted } \\
\text { prevalence ratio } \\
(95 \% \mathrm{Cl})\end{array}$} \\
\hline & $n^{2}$ & Percent $^{3}(95 \% \mathrm{Cl})$ & $n^{2}$ & Percent $^{3}(95 \% \mathrm{Cl})$ & $n^{2}$ & Percent $^{3}(95 \% \mathrm{Cl})$ & \\
\hline $\begin{array}{l}\text { Seen or talked to any health professional } \\
\text { in past } 12 \text { months }\end{array}$ & 55,877 & $83.3(82.8-83.7)$ & 891 & †92.6 (89.7-94.9) & 54,905 & $83.2(82.7-83.6)$ & $\ddagger 1.08(1.05-1.11)$ \\
\hline $\begin{array}{l}\text { Seen or talked to a specialist } \\
\text { in past } 12 \text { months }\end{array}$ & 18,955 & $26.0(25.5-26.5)$ & 558 & $\dagger 57.9(52.6-62.9)$ & 18,365 & $25.6(25.2-26.1)$ & $\ddagger 1.98(1.82-2.14)$ \\
\hline $\begin{array}{l}\text { Seen or talked to a mental health professional } \\
\text { in past } 12 \text { months }\end{array}$ & 5,848 & $8.4(8.1-8.7)$ & 154 & $\dagger 18.8(14.6-23.6)$ & 5,688 & $8.3(7.9-8.6)$ & $\ddagger 1.74(1.41-2.16)$ \\
\hline $\begin{array}{l}\text { Prescribed any medication } \\
\text { in past } 12 \text { months }\end{array}$ & 44,099 & $62.1(61.5-62.6)$ & 830 & $\dagger 86.0(82.4-89.2)$ & 43,209 & $61.8(61.3-62.4)$ & $\ddagger 1.32(1.26-1.37)$ \\
\hline $\begin{array}{l}\text { Had four or more office visits with a health professional } \\
\text { in past } 12 \text { months }\end{array}$ & 26,045 & $36.2(35.6-36.7)$ & 592 & $\dagger 57.7(52.6-62.7)$ & 25,414 & $35.9(35.4-36.4)$ & $\ddagger 1.48(1.37-1.59)$ \\
\hline Any home visits in past 12 months & 2,357 & $2.6(2.4-2.7)$ & 67 & $\dagger 5.9(3.7-8.8)$ & 2,285 & $2.6(2.4-2.7)$ & $\$ 1.80(1.25-2.59)$ \\
\hline $\begin{array}{l}\text { Any visits to a hospital emergency room } \\
\text { in past } 12 \text { months }\end{array}$ & 13,373 & $19.0(18.6-19.5)$ & 321 & $\dagger 34.5(29.6-39.6)$ & 13,028 & $18.8(18.4-19.3)$ & $¥ 1.65(1.45-1.88)$ \\
\hline $\begin{array}{l}\text { Any overnight hospital stays } \\
\text { in past } 12 \text { months }\end{array}$ & 6,524 & $8.4(8.1-8.7)$ & 185 & $\dagger 17.3(13.8-21.3)$ & 6,330 & $8.3(8.0-8.6)$ & $\mp 1.64(1.36-1.98)$ \\
\hline Any surgeries in past 12 months & 8,622 & $11.8(11.4-12.1)$ & 217 & $\dagger 22.0(17.9-26.6)$ & 8,396 & $11.6(11.3-12.0)$ & $\ddagger 1.57(1.32-1.88)$ \\
\hline
\end{tabular}

† Significantly different from that among adults without IBD $(p<0.05)$

F The difference between the estimate among adults with IBD and that among adults without IBD was statistically significant $(p<0.05)$ after adjusting for covariates in the models.

'Definitions of health care utilization variables can be found in Table 1.
2Unweighted number of participants who had received the selected service. Sample sizes may not sum to total due to missing IBD status.

${ }^{3}$ Estimates are weighted and age-adjused using the projected 2000 U.S. population distribution \#10 (https://www.cdc.gov/nchs/data/statnt/statnt20.pdf)

nealth insurance coverage, poverty level, and region.

NOTES: IBD is inflammatory bowel disease. $\mathrm{Cl}$ is confidence interval. Data are based on household interviews of a sample of the civilian noninstitutionalized population.

SOURCE: National Center for Health Statistics, National Health Interview Survey, 2015-2016, Family Core and Sample Adult Core components. 


\section{U.S. DEPARTMENT OF \\ HEALTH \& HUMAN SERVICES}

FIRST CLASS MAIL

POSTAGE \& FEES PAID

$\mathrm{CDC} / \mathrm{NCHS}$

Centers for Disease Control and Prevention

PERMIT NO. G-284

National Center for Health Statistics

3311 Toledo Road, Room 4551, MS P08

Hyattsville, MD 20782-2064

OFFICIAL BUSINESS

PENALTY FOR PRIVATE USE, $\$ 300$

For more NCHS NHSRs, visit:

https://www.cdc.gov/nchs/products/nhsr.htm.

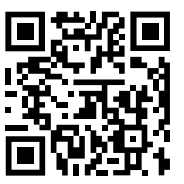

National Health Statistics Reports a Number 152 - February 24, 2021

\section{Suggested citation}

Terlizzi EP, Dahlhamer JM, Xu F, Wheaton AG, Greenlund KJ. Health care utilization among U.S. adults with inflammatory bowel disease, 2015-2016. National Health Statistics Reports; no 152. Hyattsville, MD: National Center

for Health Statistics. 2021. DOI: https://doi. org/10.15620/cdc: 100471 .

\section{Copyright information}

All material appearing in this report is in the public domain and may be reproduced or copied without permission; citation as to source, however, is appreciated.
National Center for Health Statistics

Brian C. Moyer, Ph.D., Director

Amy M. Branum, Ph.D., Acting Associate Director for Science

Division of Health Interview Statistics

Stephen J. Blumberg, Ph.D., Director Anjel Vahratian, Ph.D., M.P.H., Associate Director for Science

For e-mail updates on NCHS publication releases, subscribe online at: https://www.cdc.gov/nchs/email-updates.htm. For questions or general information about NCHS: Tel: 1-800-CDC-INFO (1-800-232-4636) • TTY: 1-888-232-6348 Internet: https://www.cdc.gov/nchs • Online request form: https://www.cdc.gov/info • CS322078 